\title{
Stereotypical Beliefs about Cyber Bullying: An Exploratory Study in terms of Myths
}

\author{
Efthymios Lampridis
}

Department of History and Ethnology - Democritus University of Thrace, Greece

Copyright $@ 2015$ Horizon Research Publishing All rights reserved.

\begin{abstract}
The present study investigates stereotypical beliefs about cyber bullying in terms of myths, a well applied concept in the study of beliefs concerning sexual aggression. The level of acceptance of cyber bullying myths (low vs. high) and the relation of myth acceptance to a number of demographic variables such as gender, field of studies, frequency of Internet use and type of online activity are examined. Also, beliefs about the forms, in terms of severity, and motives with respect to the acceptance of cyber bullying myths are assessed. University undergraduates from the Democritus University of Greece $(n=304)$ participated in the study. First, they completed a new measure assessing stereotypical beliefs about cyber bullying. Then, they ranked cyber bullying forms in terms of severity and they evaluate 5 different motives of cyber bullying. Exploratory factor analysis along with reliability testing yielded a 32 item scale with satisfactory psychometric properties. Overall, participants were found to accept cyber bullying myths moderately. Men, science and technology students, high users of the Internet and those who prefer chatting, gaming and social media when online found to accept myths higher, except those regarding the perpetrator. Significant differences regarding the ranking of cyber bullying forms and the assessment of motives were also obtained with respect to the variables mentioned above.
\end{abstract}

Keywords Cyber Bullying, Stereotypes, Beliefs, Myths

\section{Introduction}

People often use stereotypes to explain and justify violence and aggressive behavior [55]; [29]. Specifically, in the case of aggressive behavior towards women, namely sexual assault or rape, several empirical studies (Suarez \& Gadalla, [82]) point that people explain this behavior on the basis of stereotypical beliefs that tend to blame the victim and exonerate the offender. These so called "myths" have been found to determine the attributions made by people to the violent and aggressive behavior towards women [16]; [35]. Moreover, stereotypical beliefs have been found to form plausible explanations for the justification of other forms of aggression and violence as well. In the case of bullying, for example, stereotypes regarding both the victim and the offender shape particular profiles consisted of certain characteristics about physical strength, race, gender and self-esteem, among others, that become generalized and thus they serve as rules for the explanation and justification of bullying [69]; [62]; [41]. Undoubtedly, the phenomenon of bullying has been well studied in the last three decades [73] and several studies have underlined its components and shed light to the stereotypes associated with it [3]. Nevertheless, the rapid and wide expansion of the Internet has brought into researchers' attention a new form of bullying: that is, cyber bullying (CB). For many of them, $\mathrm{CB}$ is considered as equally serious to the traditional one, since the relative data point that its prevalence tends to expand over that of bullying [78]. Research on CB could be considered as young, since the vast majority of the relative studies have been published in the last ten years or so [63]. At the moment, most of these studies have investigated the magnitude of the problem [65], its forms [7] and characteristics regarding victims and perpetrators [58], bystanders [5] and the relation of cyber bullying to variables such as age and gender [76]. Thus, the idea to examine the stereotypical beliefs related to CB seems theoretically promising and empirically challenging, especially since the review of the relative literature indicates that only few studies attempted to investigate this issue [79]; [85].

\subsection{The Concept of "Myths"}

Rape myths were introduced in the social psychological literature by M Burt [18] as prejudicial, stereotypical, or false beliefs about rape that are widely shared and serve to explain and justify male sexual violence against women. Building on Burt's conceptualization, Lonsway \& Fitzgerald [51] proposed a definition of rape myths as "attitudes and beliefs that are generally false but are widely and persistently held, and that serve to deny and justify male sexual aggression against women" (p.134). A few years later, G. Bohner [11] suggested that rape myths should be considered as "wrong" rather than "false" and defined them as 
"descriptive or prescriptive beliefs about rape (i.e. about its causes, context, consequences, perpetrators, victims and their interaction) that serve to deny, downplay, or justify sexual violence that men commit against women" (p.14). Common rape myths tend to blame the victim, exonerate the perpetrator and deny the violence inherent in rape [17]. In a sense, rape myths can be viewed as a special case of Lerner's [50] "belief in a just world" theory according to which bad things can only happen to bad people and bad people get what they deserve. A key issue in the understanding of the concept of myths is the level of their acceptance. That is, all people do not share myths at the same extent and thus rape myth acceptance can be described as the extent to which a person accepts and employs rape myths as an attributional schema for explaining information concerning male sexual violence against women, yielding judgments that are biased against victims and in favor of perpetrators [31]. People who accept rape myths tend to hold stereotypical beliefs about rape such as: women tend to overreact and falsely accuse men of rape; women often fantasize about being raped; Women like to provoke men; women who are engaging in certain inappropriate or risky behaviors deserve to be raped [18]. Women who accept rape myths tend to believe that rape is a situation in which they will never find themselves in, since they are smart or righteous, avoid being provocative and they have the skills to restrain their relations with men [12]; [13]. Men, in general, tend to accept rape myths higher than women [21]. Also, younger people have been found to accept rape myths less than older ones [82]. Moreover, those who hold conservative attitudes and those who are less educated tend to accept rape myths higher [36]. Rape myth acceptance has been assessed with various scales. Among them the RMA Scale [18], the R Scale [20] the IRMA Scale [68], and, recently, the AMMSA Scale [35] seem to be the most popular. A common feature of these scales is that when assessing myths they tend to focus their attention on the beliefs regarding the responsibility of the violent behavior. In other words, they attempt to assess myths in terms of denial, downgrading or justification of the behavior and they seem to care less for the assessment of the content of the widespread stereotypical beliefs regarding the victim or the perpetrator directly. It is a methodological choice very consistent to the initial conceptualization of myths which seems, in turn, to narrow the scope of the study of myths and obstruct the assessment of these stereotypical beliefs per se.

\subsection{Cyber Bullying: Conceptual Issues, Prevalence, Age and Gender}

$\mathrm{CB}$ can be defined as an aggressive and deliberate behavior that is frequently repeated over time, carried out by a group or an individual using electronics and aimed at a victim who cannot defend him- or her-self easily [78, p. 376)]. With regard to other violent behaviors $\mathrm{CB}$ should be considered as a hostile and proactive type of indirect, relational aggression [19]. Undoubtedly, cyber and traditional bullying share a number of similar features, such as repetitiveness, intentionality and power imbalance. Also, acts like threatening, insulting, spreading rumors are common in face-to-face and electronic bullying [43]. Nevertheless, there are important differences between both forms that can be summarized as follows: In $\mathrm{CB}$ the perpetrator can be anonymous and safe behind a computer screen, free of social constraints and traditional pressures and able to remain unknown and unpunished for a long period of time [23]; [37]. Also, the perpetrator can attack simultaneously a very large number of people (e.g. the phenomenon known as bombing) and since bullying is not limited by space or time the aggressive behavior can be exhibited 24/7 and be visible for longer [67]; [80]. Then, the cyber bully is unable to observe the victim's immediate reaction [77]. According to Tokunaga [84] more than 97\% of youths in the United States are connected to the Internet in some way. Smith et al. [78] suggested that CB has now evolved to a common type of aggression that concerns middle primary and secondary school students, bearing similar or greater prevalence to traditional bullying, especially at the age of 14-15. The majority of studies regarding $\mathrm{CB}$ focused their attention on elementary and secondary school student samples. Thus, CB has been found to be most prevalent among middle schoolers. Calvete et al. [19] suggested that the peak frequency of CB is between the second and third year of Secondary Education (13-15 years). Williams and Guerra [91] also found the highest prevalence in $8^{\text {th }}$ grade (13-year-olds) comparing both with 5 th grade (10-yearolds) and 11 th grade (16-year-olds). However, recent findings [48] indicated that $\mathrm{CB}$ is also frequent among young adults. In their meta-analysis of 131 studies concerning CB, Kowalski, Giumetti, Schroeber \& Lattanner [47] highlighted the difficulty in determining the prevalence rates of $\mathrm{CB}$ victimization / perpetration due to high variations across studies regarding both theoretical and methodological issues (i.e. definition and conceptualization of $\mathrm{CB}$, diverse sampling methods and sampling incoherence, classification of participants as victims / perpetrators). Nevertheless, they pointed out that in general prevalence estimates for $\mathrm{CB}$ victimization range between approximately 10 and $40 \%$.

CB can take many different forms and occur through many different venues. Willard [90] offered a typology of $\mathrm{CB}$ forms as follows: flaming (i.e., an online fight), harassment (i.e., repetitive, offensive messages sent to a target), outing and trickery (i.e., soliciting personal information from someone and then electronically sharing that information with others without the individual's consent), exclusion (i.e., blocking an individual from buddy lists), impersonation (i.e., posing as the victim and electronically communicating negative or inappropriate information with others as if it were coming from the victim), cyber-stalking (i.e., using electronic communication to stalk another person by sending repetitive threatening communications), and denigration (slander with text messages or emails, posting defamatory comments or false rumors). $\mathrm{CB}$ can occur via instant messaging, e-mail, text 
messages, web pages, chat rooms, social networking sites, digital images, and online games [89]. In terms of gender differences, the existing data seem rather inconclusive. Although the main trend in relative findings is that boys are more prone to become perpetrators [22]; [64], while girls are more often victims [2]; [78], many studies have reported no significant differences [26]; [37]; [57]; [77] and others have found girls to be more involved in CB than boys [45].

\subsection{Cyber Bullying, Victims, Perpetrators and Bystanders: Empirical Evidence}

Several studies have investigated features and traits of victims, perpetrators and bystanders of $\mathrm{CB}$. The findings of the relative research can be summarized as follows: With respect to the victims the most common finding is that $\mathrm{CB}$ victims are individuals with low self esteem [25]; [42]; [66]. Also, victims have been found to have problematic relations with peers and to perceive less social support from their friends [19]; [9], they feel lonely [61]; [72] and are more introverted and socially isolated [75]. Moreover, they tend to exhibit poor psychological adjustment [25] and have problematic relations with their parents [1]; [53]. Finally, members of ethnic [40] or sexual [10] minorities have been found to becoming more easily targets of CB.

On the other hand, Notar, Padgett \& Roden [63] implied that minority group members are more likely to become cyber bullies. According to Poland [71] cyber bullies, contrary to the traditional ones, do not have to be stronger or faster than their victims. Then, Estell et al. [30] found that academically gifted students and general education students were less likely than students with mild disabilities to be viewed as bullies by their peers. Calvete et al. [19] suggested that adolescents who performed CB were characterized by having a lower perception of social support from their friends. Williams \& Guerra [91] also found that less peer support predicted all the types of bullying including internet bullying. Cyber bullies have been found to having been exposed to higher environmental violence and exhibit a tendency towards rule-breaking behaviors 92]. Recently, CB was associated with lower levels of both affective and cognitive empathy [4]; [74] and also with lower levels of global empathy [81]. Also, individuals who electronically perpetrate were found to have lower school commitment, dislike school more, and report lower grades [46]. Walrave \& Heirman [87] found that those who have a higher socio-economic status and those who spent more time online and consider themselves as technological experts have more chances to become cyber bullies. Furthermore, Ybarra \& Mitchell [92] found that cyber perpetrators are more frequently engaged in other maladaptive behaviors such as alcohol and tobacco use, property damaging, assaults and thievery. Last, but not least, cyber bullies have poor relationships with their parents, brought up mainly by authoritarian parents with a lack of parental attention, love and acceptance [27].

In the case of bystanders (individuals who while online might accidentally witness $\mathrm{CB}$ ), research on traditional bullying has shown that they tend to hold a negative attitude towards bullying (Salmivalli [73]). Nevertheless, recent studies [6]; [86] indicated that online bystanders often do not actively come to the victim's support. Instead, they often passively witness the bullying incident or in some cases they join in on the side of the bully. In a CB situation supporting the victim could be conceived as opposing to the bully. Thus, bystanders bear the risk of becoming targets themselves. DeSmet et al. [24] found in their study that bystanders preferred to handle $\mathrm{CB}$ offline and in person, and comforting the victim was considered more feasible than facing the bully. The fact that in CB a bystander cannot know the number of other bystanders witnessing the same incident may lead to a diffusion of responsibility and the inhibition of supportive behavior [52]. Bystanders often do not perceive themselves as actual participants although they are aware of the fact that they play a moderating role in an online harassment situation [39]. McKenna [54] associated bystander's unwillingness to engage to deindividuation and explained that in such cases a bystander would prefer to hide behind the perceived online anonymity and consequently minimize the sense of responsibility and the moral pressure for an intervention in favor of the victim.

\subsection{The Present Study}

The principal aim of the study was to investigate the stereotypical beliefs of young adults, undergraduate university students in particular, about CB. Since CB is an aggressive and violent behavior, it seemed worthwhile to investigate them through the spectrum of myths; a concept that has been successfully used in the study of other forms of aggressive behavior. It should be noted, though, that in the present study the conceptualization of myths focused more on their capacity to explain and justify aggressive behavior as widespread, wrong, stereotypical beliefs and less on their tendency to put blame on the victim and exonerate the perpetrator. In other words, the present study treats the term and the concept of myths in its general sense in order to form a functional term for the investigation of widespread stereotypical beliefs about CB. To do so a measure was developed aiming to assess beliefs about victims, perpetrators, bystanders, attitudes towards the possibility of becoming cyber victims and tendencies towards questioning the victim's honesty. Data were decided to be treated in relation to a number of demographic variables such as gender, field of studies, frequency of Internet use and type of usage (e.g. entertainment, gaming, social media, chatting etc). As reviewed earlier, gender has been found to constitute an important, yet inconclusive variable in the study of cyber bullying. Field of studies was selected because relative research has indicated that university students tend to be affected from their content of studies in shaping different mentalities in accordance to the disciplines they follow [49]. In the case of frequency of internet use research has highlighted an association between time spent online and a 
sense of ICT expertise which in turn enhances a sense of insusceptibility when online [87]. Type of Internet usage was chosen for reasons similar to that of frequency of use since technologically sophisticated individuals were found feeling comfortable and competent while spending much more time online playing online games or chatting [60].

The present study had another goal as well: To determine the acceptance of CB myths by dividing the sample to high and low with the use of median split (a well-used technique in the studies concerning rape myths, e.g. [12]; [32]; [44]). Then, to depict differences in the way participants with high or low acceptance of CB myths think of cyber bullying. In this case two things were assessed: On one hand, the severity they attribute to $\mathrm{CB}$ forms. On the other hand, their beliefs about the motives of CB. Only few studies have examined motives of $\mathrm{CB}$ and in all cases they asked cyber bullies themselves. Poland [71] reported a desire to terrorize. Hoff $\&$ Mitchell [38] found that $\mathrm{CB}$ was performed as a reaction to interpersonal problems causing anger and relative feelings that turned out to a need for revenge. Mitchell, Finkelhor, Wolak, Ybarra \& Turner [59] proposed that victims of traditional bullying would use $\mathrm{CB}$ as a means to punish their offender(s). Kowalski et al. [48] suggested that CB may be performed for fun, showing off or feeling power.

\section{Method}

\subsection{Participants and Data Collection}

The sample was made up of 304 undergraduate students of the Democritus University of Thrace, Greece originating from various parts of the country, both urban and rural. Out of them 139 were men and 165 women with mean age $=20.8$ years $(\mathrm{SD}=2.7)$. Participants were students of History, Greek literature, social administration, economics, law, medicine, civil and electronic engineering and architecture. Participants were selected randomly, they participated voluntarily and they completed the questionnaires during their classes. Data were collected in March 2014.

\subsection{Measures}

First, a large pool of items was created based on a thorough review of the literature both on $\mathrm{CB}$ and rape myths and discussion with colleagues from the fields of social psychology and research methodology. The initial item pool consisted of 58 items in Greek. Overall, the initial items could roughly be described as reflecting the following content categories: beliefs regarding the possibility to become a victim of $C B$ (e.g. $\mathrm{CB}$ is something that will not happen to me), beliefs about the victim (e.g. CB victims are usually women), beliefs about the perpetrator (e.g. cyber bullies are usually well built with great physical strength), beliefs about the bystander (e.g. When someone while he/she is online witness cyber bullying has no responsibility for that), beliefs regarding the motives of $C B$ (e.g. the motive of
$\mathrm{CB}$ is revenge), beliefs about the forms of $C B$ (e.g. no one can bully me for a photo of mine that I have uploaded), beliefs regarding society (e.g. Mass media tend to exaggerate when it comes to $\mathrm{CB}$ ), beliefs about the treatment of $C B$ (e.g. things that happen online, should stay online), beliefs that deny $C B$ (e.g. we should not take seriously anyone claiming that he/she has been cyber bullied), beliefs treating $C B$ as a random event (e.g. many times flirting on the Internet is taken as $\mathrm{CB}$ ), beliefs that exonerate the perpetrator (e.g. In many cases men driven by their passion for a woman do not become aware of the fact that their intense cyber flirting may be conceived as $\mathrm{CB}$ ), beliefs regarding lies on behalf of the victim (e.g. Some people say that they were cyber bullied to cover their own mistakes on an e mail they sent or a post they uploaded on social media).

The initial 58 items were examined and discussed further on the basis of their accordance with the underlying conceptualization of stereotypical beliefs about $\mathrm{CB}$ as myths and redundant items and items with unsuitable content were consensually deleted. This process reduced the number of items to 40 . Then 150 undergraduates from the Democritus University of Thrace, Greece completed the 40 item version of the scale. On the basis of item-to-total correlations and item means of this pilot study, 32 items were then selected for inclusion in the version of the scale that was administered to the 304 participants. Participants were asked to state the degree to which they agree or disagree on each statement on a Likert type scale ranging from 1 (strongly disagree) to 7 (strongly agree). It should be noted that special attention was paid with respect to the wording of items. Items were framed having in mind the wording of items on both the IRMA and the AMMSA scales and the considerations of Payne et al. [68] and Gerger et al. [35] regarding the need for clarity and subtle wording of the items. The psychometric properties of the scale along with the results of factor analysis are presented in details in the next part. The 32 items version of the scale along with item-to-total, item-to-subscale, item-to-scale correlations and item means are presented in the Appendix. Also, for publication purposes the scale was carefully translated into English by two independent bilingual persons (Greek to English and English to Greek). Differences in the original and the back-translated versions were discussed and resolved by joint agreement of the author and translators.

In order to assess participants' beliefs regarding the forms and motives of $\mathrm{CB}$ the following technique was employed: In the case of $\mathrm{CB}$ forms, participants were presented with a catalogue of forms equivalent to those proposed by Willard [90]. They were asked to rank these eight forms (flaming, harassment, denigration, impersonation, outing, trickery, exclusion, cyber stalking) on a hierarchical order form the most to the least severe according to their personal opinion. In the case of $\mathrm{CB}$ motives, participants were asked to complete a 5- item scale in which they had to state their agreement or disagreement to 5 statements regarding 5 different motives of $\mathrm{CB}$ (i.e. fun, revenge, punishment, jealousy, exemplification). Their answers were given on a 7 
point Likert type scale ranging from 1 (strongly disagree) to 7 (strongly agree).

In addition, respondents completed a form of demographic information regarding age, gender, field of studies, time spent online daily and type of Internet usage. For the latter, they were asked to choose and rank according to the frequency of use three out of seven types of activities (i.e. news, social media, dating, chatting, science, gaming, entertainment).

\section{Results}

Since the scale regarding CB myths was first administered in the present study it was decided for an exploratory factor analysis (EFA) to be applied. According to Tabachnick \& Fidell [83] sample size in factor analysis should exceed 300 cases. In the present study this criterion was met since $\mathrm{N}=$ 304 participants. Prior to the extraction of factors and in order to assess the suitability of the respondent data for factor analysis two tests were employed: Bartlett's test of sphericity yielded a $\chi^{2}(428)=2768.6, p<0.001$. Also, the Kaiser-Meyer-Olkin Measure of Sampling Adequacy indicated a value of the KMO index $=.80$. Thus, a Varimax rotated principal components analysis was preferred over a principal axis factoring following Pett, Lackey \& Sullivan's [70] suggestions on this matter. Kaiser's criterion (eigenvalue $>1$ rule), the Scree test and the cumulative percent of variance extracted were used as extraction rules. EFA yielded 6 components with eigenvalues greater than 1 , together explaining $65.8 \%$ of variance. The first 6 eigenvalues were: $6.06,1.94,1.68,1.53,1.31$ and 1.19 . The ratio between the first eigenvalue and the second was 3.12. In other words, the first factor explained more than 3 times as much of the total variance as any of the other factors. This ratio, as well as a visual inspection of the scree plot, suggested a one-factor solution. For interpretation purposes, items with a factor loading of at least 0.40 were considered to load on each component. In general, the components that emerged corresponded conceptually to the subscales of the scale. To test data distribution the Kolmogoroff-Smirnov test was employed. A non-significant $p$ value of .316 confirmed that data were normally distributed. Reliability analyses of the 32-item CBM scale yielded high internal consistencies. Overall Cronbach's $a=.83$. The alpha coefficients for the subscales of the scale are: Myth acceptance (MA, 5 items, $a$ $=.86$ ), victim (VIC, 6 items, $a=.84$ ), perpetrator (PER, 8 items, $a=.82$ ), bystander (BYS, 4 items, $a=.74$ ), It was not really $\mathrm{CB}$ (WNR-CB, 5 items, $a=.77$ ), the victim lied (VL, 4 items, $a=.73$ ). To further examine the internal consistency of the scale the item-total, item-to-scale and item-to-subscale correlations were examined (see Appendix) revealing that the range of the magnitude of these coefficients was moderate. Therefore, all items were retained and the mean across the 32 items was defined as a participant's CBM-Scale score.

Overall, participants were found to accept moderately $\mathrm{CB}$ Myths $\left(M_{\text {total }}=3.71, S D=1.29\right.$. In more details mean scores for the subscales of CBM-Scale yielded as follows: MA, $M=$ 4.01, $S D=1.02$, VIC, $M=3.95, S D=0.90$ ), PER, $M=4.52$, $S D=1.34$ ), BYS, $M=3.25, S D=0.96$ ), WNR-CB, $M=2.46$, $S D=0.78)$, VL, $M=3.32, S D=0.84$ ). To divide participants to those who accept high and low the CB myths median split was applied. According to that, 128 participants $(41.5 \%)$ were found to accept $\mathrm{CB}$ myths high $(\mathrm{M}=5.13, \mathrm{SD}=1.82)$, while 176 participants $(58.5 \%)$ were found to accept $\mathrm{CB}$ myths low $(\mathrm{M}=2.76, \mathrm{SD}=1.66)$.

In order to facilitate the treatment of data two categories were formed with respect to the field of studies: On one hand, those who studied Greek literature, history, social administration and law formed the Humanities and Social Sciences group, whereas those who studied civil and electronic engineering, architecture, medicine and economics formed the Sciences and Technology group. Respectively, those who reported daily use of Internet up to 2 hours formed the group of low use, while those who stated spending daily more than 2 hours grouped as high users of the Internet. Finally, according to the participants' preferences regarding the type of online activity as they were selected out of the list of 7 types of activities and ranked in hierarchical order form 1 to 3 , participants were assigned either to the group of news, science and entertainment or the group of social media, gaming and chating. Table 1 presents means differences according to gender, field of studies, frequency of Internet use and type of Internet usage. In order to test for statistically significant differences between means $t$ tests were performed.

Men were found to accept CB myths more than women. In all subscales they scored significantly higher with the exception of the subscale regarding the stereotypical beliefs about the perpetrator. In this case, men scored considerably lower in comparison to women, which in turn were found to accept highly these beliefs. It is also remarkable that men accepted more than women stereotypical beliefs that tend to question victim's honesty. The same pattern of tendencies towards the acceptance of CB myths occurred in the cases of field of studies, frequency of use of the Internet and type of Internet usage. That is, science and technology students, those who use the Internet highly on a daily basis and those who prefer to chat; play games and surfing in the social media were found to accept more $\mathrm{CB}$ myths with the exception of stereotypical beliefs regarding the perpetrator. Also, as in the case of men vs. women participants appointed to the groups mentioned above, were found to accept higher myths that doubt the victim's honesty with respect to its claim that she/he has been cyber bullied. 
.Table 1. Acceptance of CB myths with respect to gender, field of studies, daily use of Internet and type of Internet usage.

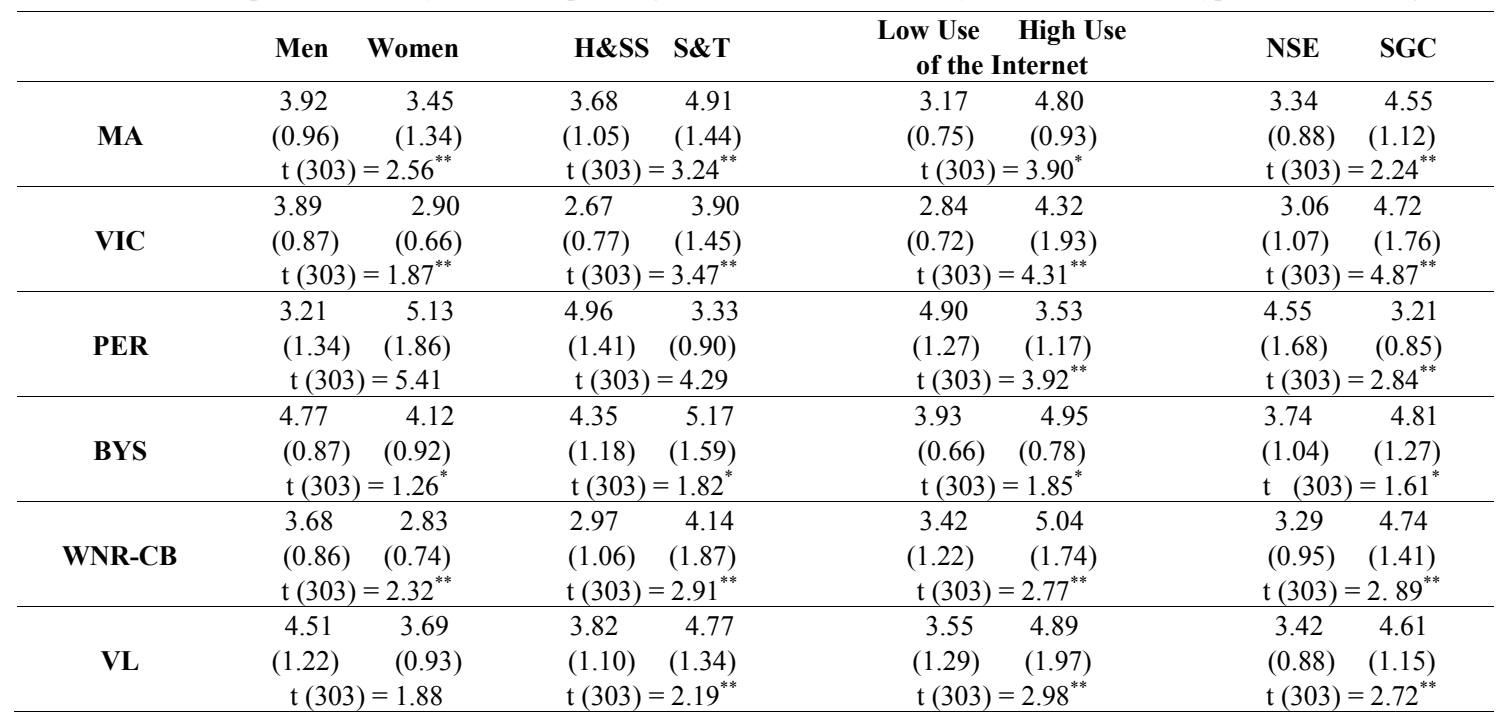

Note: ${ }^{*}=\mathrm{p}<.01,{ }^{* *}=\mathrm{p}<.001 . \mathrm{MA}=$ Myth Acceptance, $\mathrm{VIC}=$ Victim, PER $=$ Perpetrator, BYS $=$ Bystander, WNR-CB $=$ Was not really cyber bullying, VL $=$ Victim lied. H\&SS = Humanities and social Sciences, $S \& T=$ Science and Technology, NSE = News, science, entertainment, $S G C=$ Social media, gaming, chat.

Table 2. Ranking of CB forms from the most to the least severe according to CB myths acceptance.

\begin{tabular}{|c|c|c|}
\hline CB Forms & Low Acceptance & High acceptance \\
\hline Flaming & $1.88^{\mathrm{H}, \mathrm{D}, \mathrm{I}, \mathrm{O}, \mathrm{T}, \mathrm{E}, \mathrm{C} .}$ & $7.66^{\mathrm{H}, \mathrm{D}, \mathrm{I}, \mathrm{O}, \mathrm{T}, \mathrm{E}, \mathrm{C} .}$ \\
\hline Harassment & 2.73 F, I,O,T,E,C. & $6.45^{\text {F,D,I,O,T,E. }}$ \\
\hline Denigration & $3.12^{\mathrm{F}, \mathrm{I}, \mathrm{O}, \mathrm{T}, \mathrm{E}, \mathrm{C} .}$ & $3.79^{\text {F,H,O,T,E,C. }}$ \\
\hline Impersonation & $7.03^{\text {F,H,D,T,E,C }}$ & $4.24^{\text {F,H,O,T,E,C. }}$ \\
\hline Outing & $7.92^{\text {F, H, D, T,E,C. }}$ & $2.85^{\text {F,H,D,I,T,E,C. }}$ \\
\hline Trickery & $5.19^{\mathrm{F}, \mathrm{H}, \mathrm{D}, \mathrm{I}, \mathrm{O}, \mathrm{C} .}$ & $1.91^{\text {F,H,D,I,O,E,C. }}$ \\
\hline Exclusion & $4.41^{\mathrm{F}, \mathrm{H}, \mathrm{D}, \mathrm{I}, \mathrm{O}, \mathrm{C} .}$ & $5.38^{\text {F,H,D,I,O.T.C. }}$ \\
\hline Cyber stalking & $6.32^{\text {F,H,D,I,O,T,E. }}$ & $6.03^{\text {F,D,I,O,T,E. }}$ \\
\hline
\end{tabular}

Note: Due to the large number of $t$ tests applied for testing for significant differences between means, initials of each form are given in each case, pointing to the forms to which each mean was found to be statistically different. All differences were significant at least at the level of .01. Values of $t$ tests ranged from 1.01 to 4.92 for both low and high acceptance. Of course, all $t$ test values are in the disposal of the author.

Table 3. Motives of CB with respect to gender, field of studies, daily use of the Internet and acceptance of CB myths.

\begin{tabular}{ccccccccc}
\hline Motives & Men & Women & SS\&H & S\& T & Low Use & High Use & Low Acc. & High Acc. \\
\hline Fun & $5.77^{\mathrm{J}, \mathrm{R}, \mathrm{P}, \mathrm{E}}$ & $3.30^{\mathrm{J}, \mathrm{R}, \mathrm{P}, \mathrm{E}}$ & $3.14^{\mathrm{J}, \mathrm{R}, \mathrm{P}, \mathrm{E}}$ & $5.42^{\mathrm{J}, \mathrm{R}, \mathrm{P}, \mathrm{E}}$ & $2.73^{\mathrm{J}, \mathrm{R}, \mathrm{P}, \mathrm{E}}$ & $5.68^{\mathrm{J}, \mathrm{R}, \mathrm{P}, \mathrm{E}}$ & $3.10^{\mathrm{J}, \mathrm{R}, \mathrm{P}, \mathrm{E}}$ & $5.72^{\mathrm{J}, \mathrm{R}, \mathrm{P}, \mathrm{E}}$ \\
Jealousy & $3.27^{\mathrm{F}, \mathrm{R}, \mathrm{P}, \mathrm{E}}$ & $5.92^{\mathrm{F}, \mathrm{R}, \mathrm{P}, \mathrm{E}}$ & $5.71^{\mathrm{F}, \mathrm{R}, \mathrm{P}, \mathrm{E}}$ & $2.72^{\mathrm{F}, \mathrm{R}, \mathrm{P}, \mathrm{E}}$ & $5.31^{\mathrm{F}, \mathrm{R}, \mathrm{P}, \mathrm{E}}$ & $3.20^{\mathrm{F}, \mathrm{R}, \mathrm{P}, \mathrm{E}}$ & $5.29^{\mathrm{F}, \mathrm{R}, \mathrm{P}, \mathrm{E}}$ & $3.37^{\mathrm{F}, \mathrm{R}, \mathrm{P}, \mathrm{E}}$ \\
Revenge & $4.61^{\mathrm{F}, \mathrm{J}, \mathrm{E}}$ & $5.02^{\mathrm{F}, \mathrm{J}, \mathrm{E}}$ & $4.72^{\mathrm{F}, \mathrm{J}, \mathrm{E}}$ & $4.39^{\mathrm{F}, \mathrm{J}, \mathrm{E}}$ & $4.11^{\mathrm{F}, \mathrm{J}, \mathrm{E}}$ & $4.77^{\mathrm{F}, \mathrm{J}, \mathrm{E}}$ & $4.51^{\mathrm{F}, \mathrm{J}, \mathrm{E}}$ & $4.82^{\mathrm{F}, \mathrm{J}, \mathrm{E}}$ \\
Punishment & $4.14^{\mathrm{F}, \mathrm{J}, \mathrm{E}}$ & $4.49^{\mathrm{F}, \mathrm{J}, \mathrm{E}}$ & $4.28^{\mathrm{F}, \mathrm{J}, \mathrm{E}}$ & $3.81^{\mathrm{F}, \mathrm{J}, \mathrm{E}}$ & $3.64^{\mathrm{F}, \mathrm{J}, \mathrm{E}}$ & $4.33^{\mathrm{F}, \mathrm{J}, \mathrm{E}}$ & $4.32^{\mathrm{F}, \mathrm{J}, \mathrm{E}}$ & $4.31^{\mathrm{F}, \mathrm{J}, \mathrm{E}}$ \\
Exemplification & $2.10^{\mathrm{F}, \mathrm{J}, \mathrm{P}, \mathrm{P}}$ & $2.27^{\mathrm{F}, \mathrm{J}, \mathrm{R}, \mathrm{P}}$ & $2.27^{\mathrm{F}, \mathrm{J}, \mathrm{R}, \mathrm{P}}$ & $1.63^{\mathrm{F}, \mathrm{J}, \mathrm{R}, \mathrm{P}}$ & $1.85^{\mathrm{F}, \mathrm{J}, \mathrm{R}, \mathrm{P}}$ & $2.18^{\mathrm{F}, \mathrm{J}, \mathrm{R}, \mathrm{P}}$ & $2.23^{\mathrm{F}, \mathrm{J}, \mathrm{R}, \mathrm{P}}$ & $2.28^{\mathrm{F}, \mathrm{J}, \mathrm{R}, \mathrm{P}}$ \\
\hline
\end{tabular}

Note: Due to the large number of $t$ tests applied for testing for significant differences between means, initials of each motive are given in each case, pointing to the motive(s) to which each mean was found to be statistically different. All differences were significant at least at the level of .01. Values of $t$ tests ranged from 0.89 to 5.47. Of course, all $t$ test values are in the disposal of the author.

SS\&H = Social Sciences and Humanities, S\&T = Science and Technology, Acc. = Acceptance

Table 2 presents participants' ranking of the forms of $\mathrm{CB}$ with respect to its severity according to their acceptance of $\mathrm{CB}$ myths. To test for differences in the means of the $\mathrm{CB}$ forms a series of one-sample $t$ tests were applied, since data were normally distributed. Specifically, its mean corresponding to the assessment of its equivalent form in the low acceptance condition was compared to all the other means in order for statistical significant differences to be detected. The same process was repeated in the case of the responses of the participants that accepted highly CB myths. Significant differences were obtained as follows: Participants low in CB myths acceptance considered as more severe forms of $\mathrm{CB}$ outing and impersonation, cyber stalking, trickery and exclusion, denigration and harassment and, finally, flaming. On the other hand, participants' high in CB myths acceptance assessed flaming as the most severe form of CB followed by harassment and cyber stalking, exclusion, impersonation and denigration. They thought of outing as the 
second less severe form of $\mathrm{CB}$ and trickery as the least severe.

To test for differences in the beliefs concerning motives of $\mathrm{CB}$ the same process as in the case of $\mathrm{CB}$ forms was followed. Table 3 presents means according to gender, field of studies, use of the Internet and acceptance of CB myths.

Men, science and technology students, high users of the Internet and those who accept high of CB myths were found to consider fun as the most probable motive of $\mathrm{CB}$, followed by the motives of revenge and punishment (indifferently), jealousy and exemplification. On the other hand, women, social sciences and humanities students, low users of the Internet and those who accept low of $\mathrm{CB}$ myths assessed higher the motive of jealousy and then the motives of revenge and punishment (again indifferently). The motive of fun followed and the motive of exemplification, again, received the lowest scores.

\section{Discussion}

Overall, the acceptance of $\mathrm{CB}$ myths can be regarded moderate or even higher. Despite the lack of studies assessing $\mathrm{CB}$ myths the equivalent findings of research addressing myths about sexual aggression are a bit lower. According to Gerger et al., [35] and Megias, Romero-Sanchez, Duran, Moya \& Bohner [56] a total mean score of that size can imply two things: First, due to the normality of the distribution of data the myths acceptance should be considered as more higher in comparison to what its actual value indicates. Second, higher means might point to higher sensitivity in detecting myths. More on mean scores of the subscales of CBM-Scale the following remarks can be pointed out: The means of the two subscales referring to the questioning of $\mathrm{CB}$ victim's honesty are lower in comparison to the means of the other subscales. Then, the mean of the subscale regarding myth acceptance is relatively high. Thus, it could be claimed that participants although they seem to acknowledge CB as a phenomenon that really occurs, they tend to think that this will not happen to them. Research regarding myths about sexual aggression indicated results similar to the specific tension observed in the present study (Bohner et al. [17]). Also, in the case of bystander related myths, the mean scores of the items of this particular subscale point that bystanders seem to prefer a rather passive attitude towards a CB situation, to renounce any responsibility and to avoid taking action in order to stop it. Recent findings by Bastiaensens et al. [6], Holfeld [39] and McKenna [54] yielded similar results as well. It is also worth noting that participants seem to accept more the myths regarding the perpetrator in comparison to the myths regarding the victim. Nevertheless, in the case of perpetrator myths, participants seem to accept less the belief that cyber bullies surpass in physical strength, a fact that Poland [71] also stressed out. Moreover, they tend to strongly believe that adolescent boys and young men are usually the cyber bullies. Research on traditional bullying [33]; [88] has highlighted the same tendencies. In addition, in these studies girls are thought more as the victims of bullying. In the present study participants were found to hold similar beliefs about the CB victims. Also, as in the case of perpetrators, participants were found to accept less an association between a lack of physical strength and $\mathrm{CB}$ victimization. Also, despite the fact that, as noted earlier, the most common finding concerning $\mathrm{CB}$ victims is that they have low self-esteem, in the present study this specific belief was found to be the less acceptable.

When data were investigated in terms of differences according to a number of demographic variables an interesting pattern was revealed. That is, men, science and technology students, high users of the Internet and those who use Internet mainly for games, chat and social media were found to accept significantly higher CB myths except those referring to the perpetrator. The finding regarding gender differences is not a surprising one since findings from studies examining rape myth acceptance indicated that men tend to accept higher these kinds of myths [82]. The finding regarding the differences in $\mathrm{CB}$ myths acceptance with respect to the field of studies can be explained as a consequence of the fact that students of such disciplines are usually men and also as an effect that university studies have on peoples' mentalities. Specifically, Lampridis \& Papastylianou [49] while studying prosocial behavioral tendencies of Greek undergraduate students found direct associations between the field of studies and the way their participants thought about things. In the case of differences with respect to frequency of Internet use and type of online activity it could be argued that the tendency of high users and those who prefer social media, chatting or gaming while online to accept more CB myths, stem from a seeming certainty they hold that since they spent a lot of time online and especially in web venues that are thought of "high risk" for $\mathrm{CB}$ and because they are well aware of the Internet nothing bad will happen to them. Walrave \& Heirman [87] presented findings that support this suggestion. However, the question about the finding regarding the lower acceptance of perpetrator myths by men, science \& technology students, high users of the Internet and those who prefer social media, chatting and gaming remains unanswered. Could it be an indication that these participants have more possibilities to become cyber bullies? Such an explanation, although somewhat weak, should not be taken casually as wrong. Bohner, Siebler \& Schmelcher [14] and Bohner, Jarvis, Eyssel \& Siebler [15] found that the level of myth acceptance was associated with the proclivity for sexually aggressive behavior. Also, Erdur-Baker [28] and Mishna et al. [58] presented findings pointing that those who use the Internet highly on a regular basis form a false sense of control and power over the Web and its dangers and have more possibilities to become cyber bullies themselves.

Up to this point the discussion of present findings suggests that participants hold stereotypical beliefs about CB that tend to accept less or more and thus to explain and justify $\mathrm{CB}$ accordingly. Also, the acceptance of CB myths seemed to 
differ with respect to a number of demographic variables that could be claimed to form different mentalities on this matter. This tension seems to become clearer through the investigation of participants beliefs about the severity of $\mathrm{CB}$ forms and the motives of CB. For instance, those who accept CB myths low were found to consider outing and impersonation as the most severe forms and flaming as the less severe one. On the other hand, those who accept $\mathrm{CB}$ myths high ranked flaming as the most severe form of $\mathrm{CB}$ and outing as one of the less severe. These striking differentiations along with the rest of the differences obtained seem to support the former claim. That is, those who accept high $\mathrm{CB}$ myths probably due to the fact that they feel that they are aware of the Internet and its dangers they downgrade the importance of outing and trickery and they upgrade the importance of flaming since this kind of form could be considered as more related to the kind of online activities they prefer (i.e. chatting, gaming and social media). Then, those who accept $\mathrm{CB}$ myths low and thus tend to believe that $\mathrm{CB}$ is something that might happen to them as well, downgraded the importance of flaming probably due to the kind of their Internet use (i.e. news, science, entertainment) and upgraded the severity of outing and impersonation, two forms of $\mathrm{CB}$ that are considered as very common to those who do not use the Internet highly and thus do not hold a fearless attitude towards it [90].

Respectively, in the case of $\mathrm{CB}$ motives an interesting pattern was found, similar to that observed in the case of demographic variables. That is, men, science and technology students, high users of the Internet and those who accepted highly $\mathrm{CB}$ myths were found to consider fun as the most possible motive of $\mathrm{CB}$, while women, social sciences and humanities students, low users of the Internet and those who accepted low of CB myths thought of jealousy as the most possible motive. Again, a plausible explanation of this tendency might stem from that those who assessed higher fun are the ones who do not believe of having equal chances with all the others to become $\mathrm{CB}$ victims since they feel confident about their IT skills and knowledge of the Web. They downgrade the importance of CB by presenting it as a childish act. In this way they question the seriousness of $\mathrm{CB}$, indirectly exonerate the perpetrator and tend to dispel such concerns as a consequence of their fearless attitude towards it. Research on rape myths [16] has stressed out that those who accept rape myths highly tend to think of rape myths and sexual offenders similarly. On the other hand, jealousy has been found in studies regarding traditional bullying [8]; [34] to be considered as a very possible motive especially with respect to women. In the present study women and those who accept CB myths low, where the ones who assessed jealousy as the most possible motive of $\mathrm{CB}$. Contrary to fun, jealousy is a certain kind of motive that explains an aggressive behavior and by no means downgrading the importance of such an act. It does not exonerate the perpetrator and seems rather sensible to stem from women participants. It is also remarkable that all participants indifferently assessed revenge and punishment.
Hoff \& Mitchell [38] and Mitchell et al. [59] investigated cyber bullies perspectives on the motives of their actions and reported revenge and punishment, respectively, as motives identified by the bullies themselves.

Undoubtedly, the present study has certain limitations that should be taken into account. First, the present sample consisted solely of undergraduate university students. A new study in the near future should include users of the Internet from the general population, since $\mathrm{CB}$ concerns everyone who is online. Also, a study regarding CB myths focused on secondary school students would be also important as relative research [19]; [91] have highlighted the highest prevalence of $\mathrm{CB}$ at the age from 13 to 15 years. Moreover, in the present study a new instrument for the assessment of stereotypical beliefs about CB was introduced. Further research is necessary to test its reliability over time and its external validity as well. Thus, a future research should include measures that assess concepts like hostile and ambivalent sexism and right wing authoritarianism -a methodological strategy common to studies regarding the assessment of instruments assessing the acceptance of myths concerning sexual aggression [35]; [56]. Further testing of the reliability of the CBM-Scale will enable the investigation of causal relations between $\mathrm{CB}$ myths and a series of variables that the present findings have pointed out. In this study no such attempt was made since the principal aim and focus was to explore stereotypical beliefs about $\mathrm{CB}$ and highlight differences on a basic level. Therefore, it would be challenging for a future study to investigate the stereotypical beliefs of victims, perpetrators and bystanders separately and then to move a step forward and seek for explanations regarding the relation between the level of acceptance of $\mathrm{CB}$ myths and the reasons for which he/she chooses to attribute specific motives to CB. Finally, a future study might also wish to find if the degree on which someone accepts $\mathrm{CB}$ myths could predict the proclivity of CB.

\section{Conclusions}

The present study had two goals: First to investigate stereotypical beliefs about CB under the concept of myths, a well applied concept in the study of myths about another kind of aggressive behavior, that is sexual. Second, to examine $\mathrm{CB}$ myths on the basis of a number of variables (i.e. gender, field of studies, frequency of Internet use and type of online activity) that previous research had highlighted as related to this phenomenon and to depict differences in the ways people tend to think about $\mathrm{CB}$ according to their level of acceptance of such stereotypical beliefs. To do so a new measure was applied yielding satisfactory psychometric properties and providing meaningful results. Nevertheless, further research regarding its reliability and validity is necessary. In addition, the investigation of participants' beliefs about the forms of CB in terms of severity and about the motives of such a behavior came up with fruitful findings. 
It can be claimed that the present study has reached its goals as an exploratory one. More than that, though, it could be argued that it managed to set the basis for the further investigation of many interesting and challenging questions the answers of which might be useful on the level of prevention and intervention as well.

\section{APPENDIX}

The Cyber bullying Myths Sc ale (CBM-Scale)

\begin{tabular}{|c|c|c|c|c|c|c|c|c|c|c|}
\hline Item & MA & VIC & PER & BYS & $\begin{array}{l}\text { WNR- } \\
\text { CB }\end{array}$ & VL & $\begin{array}{c}\text { Item-total } \\
\text { correlations }\end{array}$ & $\begin{array}{c}\text { Item to } \\
\text { subscale }\end{array}$ & $\begin{array}{c}\text { Item to } \\
\text { scale }\end{array}$ & Means \\
\hline $\begin{array}{l}\text { Cyber bullying is something that will } \\
\text { not happen to me (1). R }\end{array}$ & .80 & & & & & & .65 & .73 & .76 & 4.32 \\
\hline $\begin{array}{l}\text { I have the same chances with everyone } \\
\text { else to become cyber bullied (7) }\end{array}$ & .74 & & & & & & .61 & .69 & .71 & 3.14 \\
\hline $\begin{array}{c}\text { I will not become cyber bullied } \\
\text { because I am aware of the possible } \\
\text { dangers and take precautions (13) R }\end{array}$ & .62 & & & & & & .50 & .64 & .61 & 4.68 \\
\hline $\begin{array}{l}\text { Even if you are using the internet } \\
\text { carefully there is always a chance to } \\
\text { become cyber bullied (18) }\end{array}$ & .61 & & & & & & .47 & .68 & .66 & 3.01 \\
\hline $\begin{array}{l}\text { My behavior in general, in both real } \\
\text { life and the internet is not a } \\
\text { provocative one, thus I will not } \\
\text { become cyber bullied (23) R }\end{array}$ & .54 & & & & & & .41 & .62 & .65 & 4.91 \\
\hline $\begin{array}{l}\text { Cyber bullying victims are usually } \\
\text { over-protected from their families and } \\
\text { over-sensitive individuals (2) }\end{array}$ & & .79 & & & & & .72 & .71 & .68 & 3.34 \\
\hline $\begin{array}{c}\text { Cyber bullying victims are usually } \\
\text { women (8) }\end{array}$ & & .73 & & & & & .64 & .70 & .69 & 5.23 \\
\hline $\begin{array}{c}\text { Cyber bullying victims are usually } \\
\text { individuals with limited physical } \\
\text { strength (14) }\end{array}$ & & .66 & & & & & .61 & .64 & .62 & 2.28 \\
\hline $\begin{array}{c}\text { Cyber bullying victims are usually } \\
\text { individuals with low self-esteem (19) }\end{array}$ & & .64 & & & & & .56 & .66 & .60 & 2.84 \\
\hline $\begin{array}{c}\text { Cyber bullying victims are usually } \\
\text { lonely individuals, without many } \\
\text { friends (24) }\end{array}$ & & .60 & & & & & .52 & .60 & .63 & 5.11 \\
\hline $\begin{array}{l}\text { Homosexuals (men and women) have } \\
\text { more chances to become cyber bullied } \\
\text { (27) }\end{array}$ & & .59 & & & & & .48 & .61 & .62 & 4.92 \\
\hline $\begin{array}{c}\text { Cyber bullies are usually individuals } \\
\text { who come from problematic families } \\
\text { (3) }\end{array}$ & & & .72 & & & & .69 & .73 & .70 & 4.01 \\
\hline $\begin{array}{c}\text { In most cases cyber bullies are } \\
\text { disturbed individuals with a } \\
\text { pathological tendency towards } \\
\text { bullying }(9) \\
\end{array}$ & & & .58 & & & & .61 & .66 & .62 & 4.97 \\
\hline Cyber bullies are usually men (15) & & & .69 & & & & .55 & .68 & .70 & 5.29 \\
\hline $\begin{array}{c}\text { Cyber bullies are usually lonely } \\
\text { individuals, without many friends (20) }\end{array}$ & & & .62 & & & & .50 & .62 & .64 & 5.12 \\
\hline $\begin{array}{c}\text { In most cases cyber bullies are } \\
\text { individuals who had not love and } \\
\text { affection from others }(25)\end{array}$ & & & .59 & & & & .47 & .64 & .60 & 4.88 \\
\hline $\begin{array}{l}\text { Cyber bullies are usually well built, } \\
\text { with great physical strength (28) }\end{array}$ & & & .55 & & & & .44 & .61 & .58 & 3.79 \\
\hline $\begin{array}{l}\text { Cyber bullies are usually foreigners } \\
\text { (not Greeks) (30) }\end{array}$ & & & .50 & & & & .41 & .59 & .55 & 2.45 \\
\hline $\begin{array}{c}\text { Cyber bullies are usually young } \\
\text { individuals, adolescents or early adults } \\
(31)\end{array}$ & & & .42 & & & & .40 & .60 & .62 & 5.65 \\
\hline $\begin{array}{c}\text { When someone while he/she is online } \\
\text { witness cyber bullying has no } \\
\text { responsibility for that (4) }\end{array}$ & & & & .61 & & & .59 & .71 & .68 & 4.57 \\
\hline $\begin{array}{l}\text { When someone witness cyber bullying } \\
\text { while he/she is online there is nothing }\end{array}$ & & & & .60 & & & .53 & .65 & .62 & 3.92 \\
\hline
\end{tabular}




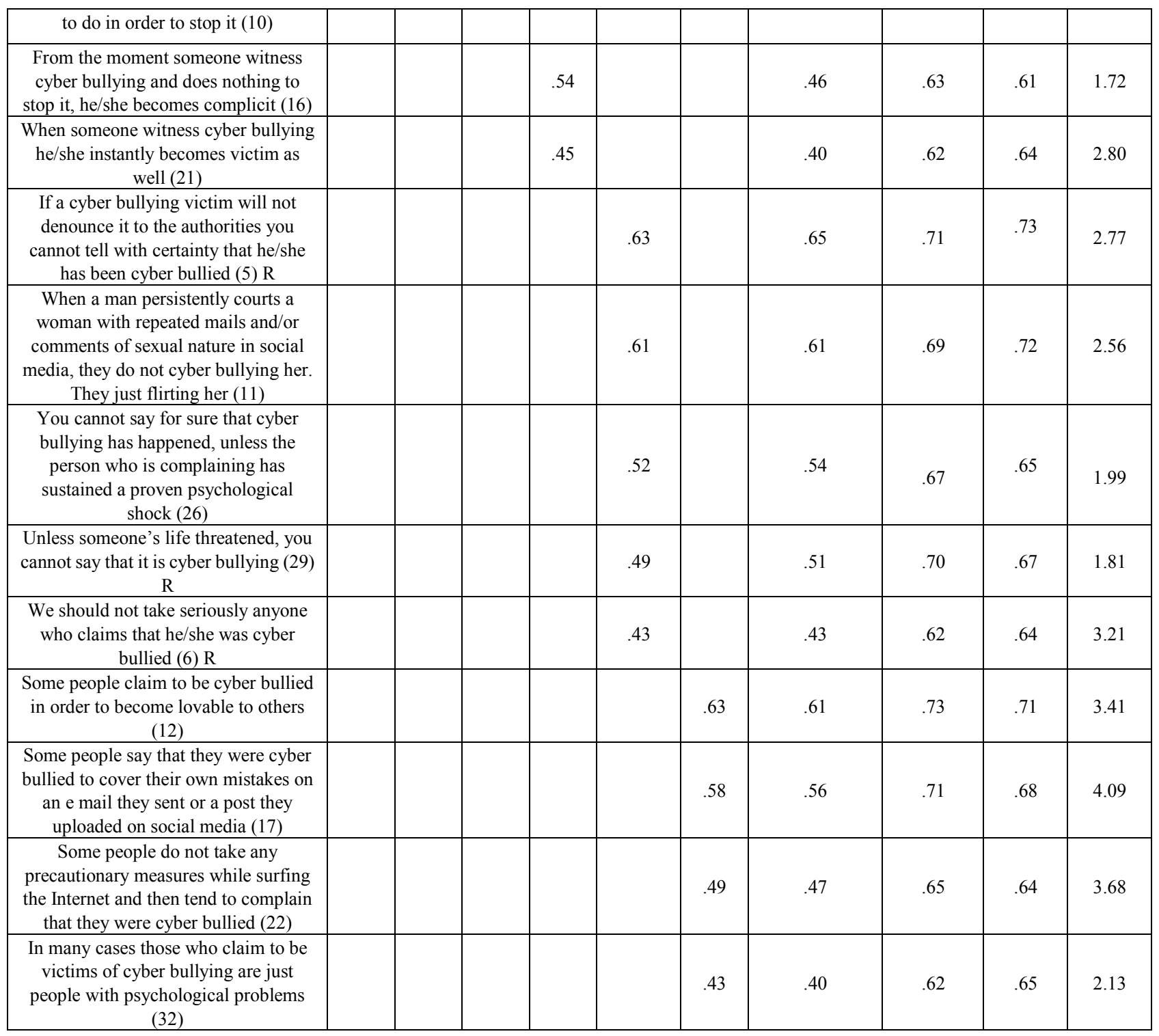

Note: $\mathrm{R}$ indicates reverse scoring. Numbers in parentheses indicate the place of the item in the scale. MA $=$ Myth acceptance, $\mathrm{VIC}=\mathrm{Victim}, \mathrm{PER}=$ Perpetrator, BYS = Bystander, WNR-CB $=$ Was not really cyber bullying, VL = Victim lied.

\section{REFERENCES}

[1] Accordino, D. B., \& Accordino, M. P. (2011). An exploratory study of face-to-face and cyberbullying in sixth grade students. American Secondary Education, 40, 14-30.

[2] Adams, C. (2010). Cyberbullying: how to make it stop. Instructor (1999), 120, 44-49. Retrieved from http://search.proquest.com/docview/754127623?accountid=1 2793, in December, $19^{\text {th }}, 2014$.

[3] Aluede, O., Adeleke, F., Omoike, D., Afen-Akpaida, J. (2008). A review of the extent, nature, characteristics and effects of bullying behaviour in schools. Journal of Instructional Psychology, 35, 151 - 158.

[4] Ang, R. P., \& Goh, D. H. (2010). Cyberbullying among adolescents: The role of affective and cognitive empathy, and gender. Child Psychiatry and Human Development, 41, 387-

\section{7. doi:10.1007/s10578-010-0176-3}

[5] Barlinska, J., Szuster, A., \& Winiewski, M. (2013). Cyber bullying among adolescent bystanders: Role of the communication medium, form of violence and empathy. Journal of Community and Applied Social Psychology, 23, 37 -51 .

[6] Bastiaesens, S., Vandebosch, H., Poels, K., Van kleemput, K., DeSmet, A., \& De Bourdeaudhuij, I. (2014). 'Can I afford to help?' How affordances of communication modalities guide bystanders' helping intentions towards harassment on social network sites. Behaviour and Information Technology, doi:10.1080/0144929X.2014.983979

[7] Beran, T., \& Li, Q. (2005). Cyber harassment: A study of a new method for an old behavior. Journal of Educational Computing Research, 32, $265-277$.

[8] Besag, V.E. (2006). Understanding Girls' Friendships, Fights and Feuds: A Practical approach to girls' bullying. Open University Press: Berkshire. 
[9] Bjoerkqvist, K., Oesterman, K., Lagerspetz, K. M. J., Landau, S. F., Caprara, G. V., \& Fraczek, A. (2001). Aggression, victimization, and sociometric status: Findings from Finland, Israel, Italy, and Poland. In J. M. Ramirez \& D. S. Richardson (Eds.), Cross-cultural approaches to research on aggression and reconciliation (pp. 111-119). New York: Nova Science Publishers.

[10] Blumenfeld, W.J., \& Cooper, R.M. (2010). LGBT and allied youth responses to cyber bullying: Policy implications. The International Journal of Critical Pedagogy, 3, 114 - 133.

[11] Bohner, G. (1998). Vergewaltigungsmythen [Rape Myths]. Landau, Germany: Verlag Empirische Padagogik.

[12] Bohner, G., Lampridis, E. (2004). Expecting to meet a rape victim affects women's self-esteem: The moderating role of rape myth acceptance. Group Process Intergroup Relations, 7, $77-88$.

[13] Bohner, G., Siebler, F., Raaijmakers, Y. (1999). Salience of rape affects self-esteem: Individual versus collective self-aspects. Group Process Intergroup Relations, 2, 191-199.

[14] Bohner, G., Siebler, F., \& Schmelcher, J. (2006). Social norms and the likelihood of raping: Perceived rape myth acceptance of others affects men's rape proclivity. Personality and Social Psychology Bulletin, 32, 286-297. doi: $10.1177 / 0146167205280912$

[15] Bohner, G., Jarvis, C. I., Eyssel, F., \& Siebler, F. (2005). The causal impact of rape myth acceptance on men's rape proclivity: Comparing sexually coercive and noncoercive men. European Journal of Social Psychology, 35, 819-828. doi: $10.1002 /$ ejsp. 284

[16] Bohner, G., Eyssel, F., Pina, A., Siebler, F., \& Viki, G.T (2009). Rape myth acceptance: Cognitive, affective and behsvioural effects of beliefs that blame the victim and exonerate the perpetrator. In M. Horvath \& J. Brown (Eds.), Rape: Challenging contemporary thinking (pp. 17 - 45). Devon, UK: Willan Publishing.

[17] Bohner, G., Pina, A., Viki, G. T., \& Siebler, F. (2010). Using social norms to reduce men's rape proclivity: Perceived rape myth acceptance of out-groups may be more influential than that of in-groups. Psychology, Crime and Law, 16, 671-693.

[18] Burt, M.R. (1980). Cultural myths and supports of rape. Journal of Personality and Social Psychology, 38, 217-230.

[19] Calvete, E., Orue, I., Estévez, A., Villardón, L., \& Padilla, P. (2010). Cyberbullying in adolescents: Modalities and aggressors' profile. Computers in Human Behavior, 26, $1128-1135$

[20] Costin, F. (1985). Beliefs about rape and women's social roles. Archives of Sexual Behaviour, 14, 319-325.

[21] Davies, M., Gilston, J., \& Rogers, P. (2012). Examining the relationship between male rape myth acceptance, female rape myth acceptance, victim blame homophobia, gender roles and ambivalent sexism. Journal of Interpersonal Violence, 27, $2807-2823$.

[22] Dehue, F., Bolman, C., \& Völlink, T. (2008). Cyber bullying: Youngsters' experiences and parental perception. CyberPsychology \& Behavior, 11, 217-223. doi:10.1089/cpb.2007.0008

[23] Dempsey, A. G., Sulkowski, M. L., Dempsey, J., \& Storch, E. A. (2011). Has cyber technology produced a new group of peer aggressors? Cyberpsychology, Behavior, and Social Networking, 14, 297-302. doi:10.1089/cyber.2010.0108

[24] DeSmet, A., Veldeman, C., Poels, K., Bastiaensens, S., Van Cleemput, K., Vandebosch, H., \& De Bourdeaudhuij, I. (2013). Determinants of self-reported bystander behavior in cyberbullying incidents amongst adolescents. Cyberpsychology, Behavior, and Social Networking. doi:10.1089/cyber.2013.0027

[25] Didden, R., Scholte, R. H. J., Korzilius, H., de Moor, J. M. H., Vermeulen, A., O'Reilly, M., Lang, R., \& Lancioni, G. E. (2009). Cyberbullying among students with intellectual and developmental disability in special education settings. Developmental Neurorehabilitation, 12, 146-151. doi: $10.1080 / 17518420902971356$.

[26] Dilmac, B. (2009). Psychological needs as a predictor of cyber bullying: A preliminary report on college students. Educational Sciences: Theory and Practice, 9, 1307-1325.

[27] Dilmac, B., \& Aydoğan, D. (2010). Parental Attitudes as a Predictor Of Cyber Bullying among Primary School Children. International Journal of Psychological and Brain Sciences, 2, 227-231.

[28] Erdur-Baker, Ö. (2010). .Cyberbullying and its correlation to traditional bullying, gender and frequent and risky usage of internet-mediated communication tools. New Media \& Society, 12, 109-125. doi: 10.1177/1461444809341260.

[29] Esqueda, C.W., \& Harrison, L.A. (2005). The influence of gender role stereotypes, the women's race and level of provocation and resistance on domestic violence culpability attributions. Sex Roles, 53, $821-834$.

[30] Estell, D. B., Farmer, T. W., Irvin, M. J., Crowther, A., Akos, P., \& Boudah, D. J. (2009). Students with exceptionalities and the peer group context of bullying and victimization in late elementary school. Journal of Child \& Family Studies, 18, 136-50.

[31] Eyssel, F. \& Bohner, G. (2011). Schema effects of rape myth acceptance on judgments of guilt and blame in rape cases: The role of perceived entitlement to judge. Journal of Interpersonal Violence, 26, 1579-1605.

[32] Frese, B., Moya, M., \& Megias, J.L. (2004). Social Perception of Rape How Rape Myth Acceptance Modulates the Influence of Situational Factors. Journal of Interpersonal Violence, 19, $143-161$.

[33] Frisen,A.,Jonsson,A.,\& Persson,C. (2007). Adolescents' perception of bullying: who is the victim? Who is the bully? What can be done to stop bullying? Adolescence, 42, 649-761.

[34] Garandeau, C., \& Cillessen, A. (2006). From indirect aggression to invisible aggression: A conceptual view on bullying and peer group manipulation. Aggression and Violent Behavior, 11, 641-654.

[35] Gerger, H., Kley, H., Bohner, G., \& Siebler, F. (2007). The acceptance of modern myths about sexual aggression scale: Development and validation in German and English. Aggressive Behavior, 33, 422 - 440.

[36] Hammond, E.M., Berry, M.A., \& Rodriguez, D.N. (2011). The influence of rape myth acceptance, sexual attitudes and beliefs in a just world on attributions of responsibility in a date rape scenario. Legal and Criminological Psychology, 16, 
$242-252$.

[37] Hinduja, S., \& Patchin, J. W. (2008). Cyberbullying: An exploratory analysis of factors related to offending and victimization. Deviant Behavior, 29, 129-156. doi:10.1080/01639620701457816

[38] Hoff, D. L., \& Mitchell, S. N. (2009). Cyberbullying: Causes, effects, and remedies. Journal of Educational Administration, $47,652-665$.

[39] Holfeld, B. (2014). Perceptions and attributions of bystanders to cyber bullying. Computers in Human Behavior, 38, $1-7$. doi: 10.1016/j.chb.2014.05.012

[40] Howlett-Brandon, M. (2014). Cyber bullying: An examination of gender, race, ethnicity and environmental factors from the national crime victimization survey: Student crime supplement, 2009. VCU Theses and Dissertations. Paper 3470.

[41] Jannsen, I., Craig, W.M., Boyce, W.F., Pickett, W. (2004). Associations between overweight and obesity with bullying behaviors in school- aged children. Pediatrics, 113, 1187 1194.

[42] Juvonen, J., \& Gross, E. F. (2008). Extending the school grounds? Bullying experiences in cyberspace. Journal of School Health, 78, $496 \quad-\quad 505$. doi:10.1111/j.1746-1561.2008.00335.x

[43] Katzer, C., Fetchenhauer, D., \& Belschak, F. (2009). Cyberbullying: Who are the victims? A comparison of victimization in Internet chatrooms and victimization in school. Journal of Media Psychology, 21, 25-36. doi:10.1027/1864-1105.21.1.25

[44] Koo, K.H., Stephens, K.A., Lindgren, K.P., \& George, W.H. (2012). Misogyny, Acculturation, and Ethnic Identity: Relation to Rape-Supportive Attitudes in Asian American College Men. Archives of Sexual Behavior, 41, 1005 - 1014. doi: 10.1007/s10508-011-9729-1

[45] Kowalski, R. M., \& Limber, S. P. (2007). Electronic bullying among middle school students. Journal of Adolescent Health, 41, 22 - 30. doi:10.1016/j.jadohealth.2007.08.017

[46] Kowalski, R. M., \& Limber, S. P. (2013). Psychological, physical, and academic correlates of cyberbullying and traditional bullying. Journal of Adolescent Health, 53, S13S20. doi:10.1016/j.jadohealth.2012.09.018

[47] Kowalski, R. M., Giumetti, G. W., Schroeder, A. N., \& Lattanner, M. R. (2014). Bullying in the digital age: A critical review and meta-analysis of cyberbullying research among youth. Psychological Bulletin. Advance online publication. http://dx.doi.org/10.1037/a0035618

[48] Kowalski, R. M., Giumetti, G. W., Schroeder, A. N., \& Reese, H. (2012). Cyberbullying among college students: Evidence from multiple domains of college life. In C. Wankel \& L. Wankel (Eds.), Misbehavior online in higher education (pp. 293-321). Bingley, United Kingdom: Emerald.

[49] Lampridis, E., \& Papastylianou, D. (2014). Prosocial behavioural tendencies and orientation towards individualism-collectivism of Greek young adults, International Journal of Adolescence and Youth, doi: $10.1080 / 02673843.2014 .890114$

[50] Lerner, M.J. (1980). The Belief in a Just World: A Fundamental Delusion. New York: Plenum Press.
[51] Lonsway, K.A., \& Fitzgerald, L.F. (1994). Rape myths: In review. Psychology of Women Quarterly, 18, 133-164.

[52] Machackova, H., Dedkova, L., Sevcikova, A., \& Cema, A. (2013). Bystander's support of cyber bullied schoolmates. Journal of Community and Applied Social Psychology, 23, 25 -36. doi: $10.1002 /$ casp. 2135

[53] Makri-Botsari, E., \& Karagianni, G. (2014). Cyber bullying in Greek adolescents: The role of parents. Procedia - Social and Behavioral Sciences, 116, 3241 - 3253. doi:10.1016/j.sbspro.2014.01.742

[54] McKenna, K. Y. A. (2008). Influence on the nature and functioning of social groups. In A. Barak (Ed.), Psychological Aspects of Cyberspace: Theory, research and applications (pp. 228-242). New York, NY: Cambridge University Press.

[55] McKimmie, B.M., Masser, B.M., Bongiorno, R. (2014). What counts as rape? The effect of offense prototypes, victim stereotypes and participant gender on how the complainant and defendant are perceived. Journal of Interpersonal Violence, 29, 2273 - 2303.

[56] Megías, J. L., Romero-Sánchez, M., Durán, M., Moya, M., \& Bohner, G. (2011). Spanish validation of the Acceptance of Modern Myths about Sexual Aggression Scale (AMMSA). Spanish Journal of Psychology, 14, 912-925. doi: 10.5209/rev_SJOP.2011.v14.n2.37

[57] Mishna, F., Cook, C., Gadalla, T., Daciuk, J., \& Solomon, S. (2010). Cyber bullying behaviors among middle and high school students. American Journal of Orthopsychiatry, 80, 362-374. doi:10.1111/j.1939-0025.2010.01040.x

[58] Mishna, F., Khoury-Kassabri, M., Gadalla, T., Daciuk, J. (2012). Risk factors for involvement in cyber bullying: Victims, bullies and bully - victims. Children and Youth Services Review, 34, $63-70$.

[59] Mitchell, K. J., Finkelhor, D., Wolak, J., Ybarra, M. L., \& Turner, H. (2011). Youth Internet victimization in a broader victimization context. Journal of Adolescent Health, 48, 128134. doi:10.1016/j.jadohealth.2010.06.009

[60] Morahan-Martin, J., \& Schumacher, P. (2000). Incidence and correlates of pathological Internet use among college students. Computers in Human Behavior, 16, 2-13.

[61] Nansel, T. R., Overpeck, M., Pilla, R. S., Ruan, W., Simons-Morton, B., \& Scheidt, P. (2001). Bullying behaviors among U.S. youth: Prevalence and association with psychosocial adjustment. JAMA: Journal of the American Medical Association, 285, 2094-2100. doi:10.1001/jama.285 .16.2094

[62] Navarro, R., Larranaga, E., Yubero, S. (2011). Bullying victimization problems and aggressive tendencies in Spanish secondary schools students: the role of gender stereotypical traits. Social Psychology of Education, 14, 457 - 473.

[63] Notar, C.E., Padgett, S., Roden, J. (2013). Cyber bullying: A review of the literature. Universal Journal of Educational Research, 1, 1 -9. doi: 10.13189/ujer.2013.010101

[64] Olweus, D. (2010). Understanding and researching bullying: Some critical issues. In S. R. Jimerson, S. M. Swearer, \& D. L. Espelage (Eds.), The handbook of school bullying: An international perspective (pp. $9-33$ ). New York: Routledge.

[65] Patchin, J.W., \& Hinduja, S. (2006). Bullies move beyond the 
schoolyard: a preliminary look at cyber bullying. Youth Violence and Jouvenille Justice, 4, 148 - 169.

[66] Patchin, J. W., \& Hinduja, S. (2010). Cyberbullying and self-esteem. Journal of School Health, 80, 614-621. doi:10.1111/j.1746-1561.2010.00548.x

[67] Patchin, J. W., \& Hinduja, S. (2011). Traditional and nontraditional bullying among youth: A test of general strain theory. Youth \& Society, 43, 727-751. doi:10.1177/0044118X10366951

[68] Payne, D.L., Lonsway, K.A., \& Fitzgerald, L.F. (1999). Rape myth acceptance: Exploration of its structure and its measurement using the Illinois Rape Myth Acceptance Scale. Journal of Research on Personality, 33, 27-68.

[69] Peguero, A.A., \& Williams, L.M. (2013). Racial and ethnic stereotypes and bullying victimization. Youth and Society, 46, $545-564$

[70] Pett, M.A., Lackey, N.R., \& Sullivan, J.J. (2003). Making Sense of Factor Analysis: The use of factor analysis for instrument development in health care research. California: Sage Publications Inc.

[71] Poland, S. (2010). Cyberbullying continues to challenge educators. District Administration, 46, 55.

[72] Sahin, M. (2012). The relationship between the cyberbullying/ cybervictimization and loneliness among adolescents. Children and Youth Services Review, 34, 834837. doi:10.1016/j.childyouth.2012.01.010

[73] Salmivalli, C. (2010). Bullying and the peer group; A review. Aggression and Violent Behavior, 15, $112-120$.

[74] Schultze-Krumbholz, A., \& Scheithauer, H. (2009b). Social-behavioral correlates of cyberbullying in a German student sample. Zeitschrift für Psychologie/Journal of Psychology, 217, 224-226. doi:10.1027/0044-3409.217.4.22 4

[75] Siegle, D. (2010). Cyberbullying and sexting: Technology abuses of the 21 st century. Gifted Child Today, 33, 14-65.

[76] Slonje, R., \& Smith, P.K. (2007). Cyber bullying: Another main type of bullying? Scandinavian Journal of Psychology, $49,147-154$.

[77] Slonje, R., \& Smith, P. K. (2008). Cyberbullying: Another main type of bullying? Scandinavian Journal of Psychology, 49, 147-154. doi:10.1111/j.1467-9450.2007.00611.x

[78] Smith, P. K. , Mahdavi, J., Carvalho, M., Fisher, S., Russell, S., \& Tippett, N. (2008). Cyberbullying: Its nature and impact in secondary school pupils. Journal of Child Psychology and Psychiatry, 49, 376-385.

[79] Sontag, L. M., Clemans, K. H., Graber, J.A., \& Lyndon, S. (2011). Traditional and cyber aggressors and victims: A comparison of psychosocial characteristics. Journal of Youth \& Adolescence, 40, 392-404.
[80] Sourander, A., Klomek, A.B., Ikonen, M., Lindroos, J., Luntamo, T., Koskelainen, M., Ristkari, T., \& Helenius, H. (2010). Psychosocial Risk Factors Associated With Cyberbullying Among Adolescents: A Population-Based Study. Archives of General Psychiatry, 67, 720-728.

[81] Steffgen, G., König, A., Pfetsch, J., \& Melzer, A. (2011). Are cyberbullies less empathic? Adolescents' cyberbullying behavior and empathic responsiveness. Cyberpsychology, Behavior, and Social Networking, 14, 643-648. doi:10.1089/cyber.2010.0445

[82] Suarez, E., \& Gadalla, T.M. (2010). Stop blaming the victim: A meta-analysis on rape myths. Journal of Interpersonal Violence, 25, 2010 - 2035.

[83] Tabachnick, B.G., \& Fidell, L.S. (2007). Using Multivariate Statistics. Boston: Pearson Education Inc.

[84] Tokunaga, R.S. (2010). Following you home from school: A critical review and synthesis on research on cyber bullying victimization. Computers in Human Behavior, 26, 277 - 287.

[85] Underwood, M. K. \& Rosen, L. H. (2011). Gender and bullying: Moving beyond mean differences to consider conceptions of bullying processes by which bullying unfolds, and cyber bullying. In D. L. Espelage \& S. M. Swearer (Eds.), Bullying in North American schools (2nd Ed.). New York: Routledge.

[86] Van Cleemput, K., Vandebosch, H., \& Pabian, S. (2014). Personal characteristics and contextual factors that determine "helping," "joining in," and "doing nothing" when witnessing cyberbullying: Bystander Behavior in Cyberbullying. Aggressive Behavior, 40, 383-396. doi:10.1002/ab.21534

[87] Walrave, M., \& Heirman, W. (2011). Cyberbullying: Predicting victimization and perpetration. Children \& Society, 25, 59-72. doi:10.1111/j.1099-0860.2009.00260.x

[88] Wang, J., Iannotti, R. J., \& Nansel, T. R. (2009). School bullying among adolescents in the United States: Physical, verbal, relational, and cyber. Journal of Adolescent Health, 45, 368-375. doi:10.1016/j.jadohealth.2009.03.021

[89] Whittaker, E., \& Kowalski, R.M. (2015) Cyber bullying via social media. Journal of School Violence, 14, 11-29. doi:10.1080/15388220.2014.949377

[90] Willard, N. E. (2007). Cyberbullying and cyberthreats: Responding to the challenge of online social aggression, threats, and distress. Champaign, IL: Research Press.

[91] Williams, K. R., \& Guerra, N. G. (2007). Prevalence and predictors of Internet bullying. Journal of Adolescent Health, 41, 14 - 21. doi:10.1016/j.jadohealth.2007.08.018

[92] Ybarra, M. L., \& Mitchell, K. J. (2004). Online aggressor/targets, aggressors, and targets: A comparison of associated youth characteristics. Journal of Child Psychology and Psychiatry, 45, 1308-1316. doi:10.1111/j.1469-7610.2004.00328.x 